\title{
Killing, letting die and euthanasia
}

\author{
Douglas N Husak Rutgers College, Rutgers University, New Brunswick, New fersey
}

\begin{abstract}
Author's abstract
Medical ethicists debate whether or not the moral assessment of cases of euthanasia should depend on whether the patient is ' $k$ illed' or 'allowed to die'. The usual presupposition is that a clear distinction between killing and letting die can be drawn so that this substantive question is not begged. I contend that the categorisation of cases of instances of killing rather than as instances of letting die depends in part on a prior moral assessment of the case. Hence is it trivially rather than substantively true that the distinction has moral significance. But even if a morally neutral (ie non-question begging) distinction could be drawn, its application to the euthanasia controversy is problematic. I illustrate the difficulties of employing this distinction to reach moral conclusions by critically discussing Philippa Foot's recent treatment of euthanasia. I conclude that even if an act of euthanasia is an instance of killing, and there exists a prima facie moral duty not to kill, and no more stringent duty overrides this duty, one still cannot determine such an act to be morally impermissible.
\end{abstract}

\section{Introduction}

The controversy about the moral relevance of the distinction between killing and letting die continues to rage. Proponents of each point of view offer clever examples designed to show that, ceteris paribus, the distinction has or lacks moral significance. This question is thought to have particular application to the issue of whether and under what conditions euthanasia is morally permissible.

Typically, the controverted claim is thought to be the following: once the distinction between 'active' killings and 'passive' omissions that result in death is drawn by action theorists in such a way that moral questions are not begged, the distinction can be seen to have or lack moral relevance. However, it is seldom suspected that the action theorist may be unable to draw a morally neutral distinction between killing and letting die in the first place. In Part I of this paper I will argue that a satisfactory account of this distinction (eg, an account immune from counter-examples) must, at least implicitly, refer to moral norms. Hence it is trivially true that the distinction is morally relevant. In the absence of a morally neutral distinction in action theory, parties on each side of the controversy are without a substantive issue on which to disagree. In Part II of this paper I will show that, even if the distinction between active killings and passive omissions can be drawn in a morally neutral way, its relevance for the euthanasia controversy is not as straightforward as many philosophers have supposed.

\section{Part I}

Whether behaviour is described in one way rather than another is in large part conventional, depending greatly on the purposes the description is designed to achieve. Of course, there are some clear cases in which we would describe the behaviour of an agent as a case of killing: Jones, without excuse, deliberately stabs Smith with a knife. There are equally obvious instances of letting die: Brown casually stands by and watches Smith drown, failing to employ readily available means to rescue him. But one must not be misled by clear cases on either side of the distinction to suppose that the distinction is a sharp one. For the kinds of cases about which moral philosophers have debated most vehemently, particularly in controversies about euthanasia, are those most elusive of categorisation. In these borderline cases, the tendency to describe behaviour as a case of active killing rather than of passive letting die includes a moral evaluation-if we wish to condemn the behaviour more strongly, we are more likely to describe it as killing than as letting die.

Perhaps the best strategy to support my contention is to critically examine one influential attempt to draw a morally neutral distinction between killing and letting die. According to Daniel Dinello, $x$ let $y$ die if

a) there are conditions affecting $y$, such that if they are not altered, $y$ will die.

b) $x$ has reason to believe that the performance of certain movements will alter conditions affecting $y$, such that $y$ will not die.

c) $x$ is in a position to perform such movements.

d) $x$ fails to perform these movements. ${ }^{1}$

The defect in the above criteria is illustrative of the difficulty of formulating value-free truth conditions for the proposition ' $x$ let $y$ die.' Suppose $y$ is drowning and $x$, a mediocre swimmer, is standing nearby. Anxious to rescue $y, x$ must quickly decide 
whether to dive in after $y$ or to throw $y$ a life preserver lying at his feet. Suppose further that $x$ believes (and has reason to believe) that either alternative will succeed, though in fact only the latter means will save $y$ 's life. $X$ dives in after $y$. After much thrashing about, $x$ is unsuccessful in rescuing $y$, and barely escapes drowning himself. Clearly, according to Dinello's criteria, $x$ has let $y$ die. $X$ had reason to believe that throwing the life preserver would save $y$ 's life, yet failed to do so. I suspect, however, that if $x$ were accused of letting $y$ die, he would bitterly oppose such a description of his behaviour: 'I didn't let $y$ die, I tried very hard to save him!' $X$ would be correct.

What this counter example is designed to reveal is that such criteria as the above cannot draw a morally neutral distinction between 'active' killing and 'passive' letting die. At a minimum, what must be added to such criteria to render them satisfactory is some statement about $x$ 's pursuit of alternative plans of rescue. But clearly, not just any alternative will suffice to falsify the proposition ' $x$ let $y$ die.' If $x$ had immediately enrolled in a course in lifesaving in the hope that $y$ could tread water until $x$ became a more proficient swimmer, we still would say that $x$ let $y$ die. What is required to remedy this difficulty is the inclusion not only of $x$ 's pursuit of alternatives, but also some indication of the reasonableness of such alternatives. $X$ did not let $y$ die in my counter example because the alternative he chose was one he reasonably believed would be efficacious in saving $y$.

But the inclusion of words such as 'reasonable' in such criteria sacrifices the moral neutrality of the distinction the criteria are designed to draw. What we are inclined to describe as reasonable or unreasonable depends in part on our moral evaluation of the behaviour in question. Lawyers are particularly familiar with the process by which the use of words such as 'reasonable' (or 'significant') in a standard makes the application of that standard depend in part on normative considerations that defy a purely epistemic or probabilistic analysis. ${ }^{2}$ Thus the distinction between active killing and passive letting die cannot be drawn by the action theorist in such a way that the controversy about the moral relevance of the distinction can be profitably conducted.

\section{Part II}

Even if a value-free distinction between cases of active killing and passive letting die could be drawn, the use of this distinction in the euthanasia controversy is highly problematic. In her recent article 'Euthanasia', ${ }^{3}$ Philippa Foot attempts to employ such a distinction in order to conclude that all instances of non-voluntary active euthanasia are unjustified. In this section I will argue that her reasoning in support of this conclusion is defective on grounds other than the difficulty of formulating am morally neutral distinction between active and $\overrightarrow{\overline{0}}$. passive euthanasia. The problems with Foot's? analysis are important, I believe, because similar $\vec{F}$ difficulties are encountered by many arguments? designed to establish the impermissibility of $\frac{O}{\circ}$ instances of non-voluntary active euthanasia.

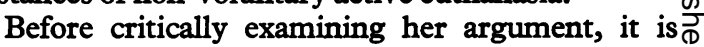
important to understand the conclusion Foot $\varrho$ attempts to prove. Two pairs of distinctions between $\%$ kinds of euthanasia are crucial: euthanasia may be $\vec{\circ}$ voluntary or involuntary, active or passive. Foot is not as clear in drawing these distinctions as one $\vec{\omega}$ would like. Euthanasia is non-voluntary when performed upon persons 'whose wishes cannot be ascertained either because they cannot properly be said to have wishes or because, for one reason or $\dot{i}$ another, we are unable to form a reliable estimate of $\bigcirc$ what they are."4 Foot is evasive concerning whereo 'the boundaries of the 'active' and 'passive' lie.' 5 She indicates that this distinction does not quite

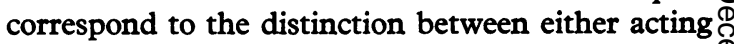
and omitting or killing and letting die, but does not $\stackrel{\mathbb{}}{I}$ elaborate on how the distinction is to be understood.

My reconstruction of Foot's argument is as follows:

I) All persons have a right to life.

2) Rights create correlative duties in other persons not to interfere with what is protected by the right.

3) The right to life creates correlative duties not to commit acts that interfere with life, but does not create duties of positive service. ${ }^{6}$

4) An act is unjustified if and only if it is contrary to virtue.

5) All acts contrary to virtue are contrary to duty or contrary to charity.

6) Active non-voluntary euthanasia is contrary to the duty of non-interference correlative to the right to life.

7) No acts of charity can justify an act that is contrary to duty; therefore

8) All instances of active non-voluntary euthanasia are contrary to virtue and hence unjustified.

The above argument is not unlike those commonly urged against proponents of active non-voluntary을. euthanasia-yet it represents, in some respects, an $\overline{\mathrm{N}}$ improvement over many such arguments. Foot realises that one does not attain virtue simply by ${ }_{0}$ doing one's duty; some virtuous acts are acts of ${ }_{\omega}^{N}$ charity. Hence, even though an instance of non- 0 voluntary active euthanasia may be contrary too duty and is therefore prima facie unjustified, it has not been shown to be unjustified simpliciter or all $\stackrel{\oplus}{+}$ things considered. To establish this latter conclusion, 7 one must show either that no instance of active non-voluntary euthanasia can be an act of charity, $\stackrel{\mathbb{Q}}{\stackrel{\mathrm{O}}{?}}$ which is absurd, or that considerations of charity $\mathbb{Q}$ cannot provide adequate justification for failure tog do one's duty. Hence Foot is committed to premise (7) if her argument is to be valid. 
It is worth noting how this argument is dependent upon a morally neutral distinction between the active and passive. My present criticism, however, is directed against premise (7). It is a philosophical truism that some failures to do one's duty are justified, all things considered. One often is justified in, for example, failing to keep his promises. It is a plausible thesis that the only adequate justification for failure to do one's duty is the need to perform some other duty that conflicts with and overrides the first duty. A moral theory should encourage acts of charity, but only to the extent that such acts do not result in the non-performance of duty. For example, parents are to be praised for donating time and money to worthwhile community projects, but not if such acts distract them from their duty to care for their infant children.

As plausible as the claim that only the existence of a conflicting, overriding duty can justify failure to perform some other duty may appear, I believe such a claim to be false. In order to provide a counterexample, it will be necessary to assume, with Foot, that the right to life does not create correlative duties of positive service. Suppose I have agreed to meet you at a designated time so that we can attend a lecture. Such an agreement is correctly thought to give rise to a prima facie duty. Supose further that on my way to your house, I witness an accident in which several persons are injured. Circumstances are such that assistance is needed, and I am in the best position to render such assistance. If premise (3) of Foot's argument is true, I have no duty to assist these victims. No one would deny, however, that my failure to assist would be contrary to virtue. By premise (5), then, my failure to assist must be contrary to charity. But if premise (7) is correct, this act of charity cannot provide justification for my failure to do my duty and meet you at the designated time. I submit that this result is unsatisfactory. Any moral theory that required me to abandon the accident victims in order not to violate my duty to you is inadequate. The precise connection between charity and duty is among the most perplexing in moral philosophy; yet it is clear that some acts of charity provide justification for failure to do one's duty.

The application of the above result to Foot's argument is straightforward. If some acts of euthanasia are acts of charity, which seems undeniable, it is misguided to maintain that such acts are nonetheless impermissible all things considered because they are contrary to duty. Justification for $\stackrel{m}{+}$ failure to do one's prima facie duty can sometimes be found in considerations of charity. In the absence of $?$ ? an argument to show that a charitable act cannot $\overrightarrow{\vec{F}}$ provide justification for failure to perform duties $\frac{?}{\circ}$ correlative to the right to life, I conclude that Foot's argument against the permissibility of non- $\frac{\overline{\bar{N}}}{\bar{n}}$ voluntary active euthanasia is unsound.

Yet Foot's failure is instructive. The general $\stackrel{\square}{\Omega}$ lesson to be learned from her mistake is that many के contemporary discussions in moral philosophy, and $\overrightarrow{0}$ about euthanasia in particular, are entirely too $-\overrightarrow{-}$ obsessed with the notions of rights and duties (and $\omega_{\sigma}$ obligations). My arguments support the principle that no conclusion concerning the wrongness (all $\pitchfork$ things considered) of a particular act can be established from a demonstration that that act if violates a duty, even in the absence of conflicting, $\bigcirc$ overriding duties.

\section{Conclusion}

Disputants concerning the permissibility of 3 euthanasia cannot rely on a morally neutral distinc- $\mathbb{D}$ tion between 'active' killings and 'passive' omissions $\vec{\oplus}$ which result in death. But even if such a value-free distinction could be formulated. its application to the euthanasia controversy would remain problematic, for some instances of euthanasia may be permissible all things considered despite theiro categorisation as 'active' killings.

\section{References and notes}

${ }^{1}$ Dinello, Daniel (1971). On Killing and Letting Die, Analysis, 3I - p. 83. Reprinted in Gorowitz, Samuel, et. al., (1976), (Eds).: Moral problems in medicine, Englewood Cliffs: Prentice-Hall, p. 28I.

${ }^{2}$ See Dworkin, Ronald (1977). Taking rights seriously. Cambridge: Harvard University Press, N. B. p. 28.

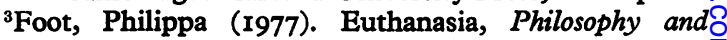
public affairs, 6' p. 85.

4 Ibid p. ro4.

${ }^{5}$ Ibid p. ror.

${ }^{6}$ Foot does not accept this premise in the unqualifiedo form in which $I$ have expressed it. Her examples indicate that the right to life can give rise to correla- $N$ tive positive duties only if there exists a special relation ship between the parties, eg, that between husband and wife, parents and children, etc. Hercu qualifications, then, are unimportant for the presento analysis. 